\title{
Is pesticide exposure a cause of obstructive airways disease?
}

\author{
Emma Doust ${ }^{1}$, Jon G. Ayres², Graham Devereux³, Finlay Dick ${ }^{4}$, \\ Joanne 0. Crawford ${ }^{1}$, Hilary Cowie ${ }^{1}$ and Ken Dixon ${ }^{1}$
}

Affiliations: ${ }^{1}$ Institute of Occupational Medicine, Edinburgh, UK. ${ }^{2}$ Institute of Occupational and Environmental Medicine, University of Birmingham, Birmingham, UK. ${ }^{3}$ Child Health, Royal Aberdeen Children's Hospital, Aberdeen, UK. 'Dept of Environmental and Occupational Medicine, University of Aberdeen King's College, Aberdeen, UK.

Correspondence: Joanne O. Crawford, Institute of Occupational Medicine, Research Avenue North, Riccarton, Edinburgh, EH14 4AP, UK. E-mail: joanne.crawfordवiom-world.org

ABSTRACT A systematic review was performed to identify any associations between pesticide exposure and the occurrence (both prevalence and incidence) of airways disease (asthma and chronic obstructive pulmonary disease) and wheezing symptoms.

PubMed, MEDLINE, Embase, Scopus, CINAHL, Google Scholar and the Cochrane Database of Systematic Reviews were searched between September 2010 and October 2010 for papers with the inclusion criteria of English language, published after 1990, peer-reviewed and nondietary exposure. From a total of 4390 papers identified, 42 were included after initial assessment of content. After evaluating the included studies for quality, those considered to be at high risk of bias were excluded, leaving a total of 23 relevant papers.

Results suggest that exposure to pesticides may be associated with prevalent asthma, but methodological issues, such as cross-sectional/case-control design, measurements of exposure and limited adjustment for confounders, limit the strength of the evidence base in this area. The association between pesticide exposure and asthma appears to be more evident and consistent in children than in adults. Exposure to pesticides may be associated with COPD; however, the strength of evidence for an association with COPD is weaker than for asthma. As the exposure metrics within each health end-point varied across studies, no metaanalyses were carried out.

0 @ERSpublications

Pesticide exposure may be associated with increased respiratory symptoms; evidence is lacking on specific pesticides http://ow/ly/U5Qr7

\section{Introduction}

Pesticides have been widely used for agricultural control of pests and weeds and as growth regulators for decades. Earlier pesticides used for this purpose, such as organochlorines (e.g. dichlorodiphenyltrichloroethane (DDT)) and organophosphates (e.g. paraquat), while extremely effective in controlling the target organisms, had marked adverse effects, particularly in terms of ecotoxicity. While use of many members of these two pesticide groups is banned in a large number of countries, use continues in other areas, particularly in the developing world where pesticide use remains largely unregulated.

This article has supplementary material available from err.ersjournals.com

Received: July 302013 | Accepted after revision: Aug 302013

Support statement: This study was supported by the Dept of Environment, Food and Rural Affairs (Defra; London, UK).

Conflict of interest: None declared.

Provenance: Submitted article, peer reviewed.

Copyright OERS 2014. ERR articles are open access and distributed under the terms of the Creative Commons Attribution Non-Commercial Licence 4.0. 
As many pesticides, especially those used on crops, are applied by spraying, exposure through inhalation is of particular concern, in addition to dermal exposure to the operator. It is well recognised that pesticides can cause acute irritant responses in the lung; this is documented in a range of surveillance schemes worldwide (e.g. the Pesticide Impact Assessment Program in the USA and the National Poisons Information Service pesticide surveillance project in the UK). In addition, it is possible that any adverse respiratory effect of pesticides might be more likely in those with pre-existing respiratory diseases, such as asthma or chronic obstructive pulmonary disease (COPD). It is also possible that repeated exposures to pesticides might increase the risk for healthy individuals developing respiratory conditions, such as asthma or COPD [1]. Asthma is most common in childhood, with prevalence rates ranging between $2 \%$ and $35 \%$ [2, 3]. It is believed that early-life environmental exposures play a key role in defining those children who develop asthma. Asthma is still common in adulthood, affecting $\sim 2-12 \%$ of adults worldwide [4] and it has been estimated that $5-10 \%$ of new cases of asthma arising in adults of working age are due to occupation [5]. Occupational factors contribute $\sim 15 \%$ of the burden of COPD [6]. What is currently not known is whether regular occupational pesticide exposure is contributing to the incidence and prevalence of respiratory disease.

The aim of this systematic review was to identify any associations between pesticide exposure and the occurrence (both prevalence and incidence) of airways disease (asthma and COPD). The occurrence of wheeze was included in this study as the diagnosis of asthma, in epidemiological terms, has been the matter of much debate. Some authorities accept a positive answer to the question "Has a doctor ever told you that you have asthma?"; others accept a positive response to a question on repeated episodes of wheeze, while others require the presence of relevant symptoms plus positive bronchial responsiveness.

\section{Methods}

A search strategy was developed that included terms to cover population, particular chemicals, exposure route, exposure assessment, health outcomes and study designs. The full search strategy and findings are reported elsewhere [7]. Inclusion and exclusion criteria were also set and included articles published in the English language since 1990, but excluded dietary routes for the pesticides. The year 1990 was chosen to limit those studies published earlier, which may not be as relevant with respect to the type of pesticides used or how they were used.

Seven databases (PubMed, MEDLINE, Embase, Scopus, CINAHL, Google Scholar and the Cochrane Database of Systematic Reviews) were searched between September 2010 and October 2010 using a detailed search strategy [7]. The databases searched were chosen to cover a broad range of sources, including medical and scientific literature, and both primary research and systematic reviews. These databases were thought to capture the most relevant publications available. The main outcomes of interest were respiratory airways diseases and wheeze in both children and adults.

On completion of the searches, title and abstract screenings were carried out independently by two researchers. Where there was disparity, this was discussed and a consensus reached. From the remaining abstracts, full copies of the publication were obtained and a second, full paper screening was carried out independently by two academic physicians. This resulted in the further removal of papers that did not meet the inclusion criteria of the review (English language, published after 1990, peer-reviewed and exposure not through diet). Disagreements between assessors were resolved by discussion.

The remaining papers were then assessed for quality independently by the same two physicians using 14 criteria based on the Scottish Intercollegiate Guidelines Network (SIGN) [8]. The papers were assigned a summary grade for likelihood of bias as either ++ (low risk of bias), + (unclear/unknown risk of bias) or - (high risk of bias), with any discrepancies in grading being resolved by consensus. During this review stage, further papers were removed that failed to meet the inclusion criteria.

\section{Results}

In total, 4390 publications were identified from the searches. After initial title and abstract screening this was reduced to 524 publications, removal of duplicates resulted in 348 screened abstracts for consideration (fig. 1). A second stage of paper screening was carried out on full manuscripts. This resulted in the removal of an additional 195 papers that did not fit the inclusion criteria of the review. A further 111 papers were removed because their topics were acute pesticide poisonings or military exposure (which is atypical of and considerably higher than occupational/bystander exposure), or they were case studies or nonsystematic reviews, or they were not in English [7]. This systematic review focuses on the occurrence (both prevalence and incidence) of airways disease and wheeze; therefore, papers focussing solely on exacerbation of established airways disease, without separating out symptoms such as wheeze, were also excluded.

A total of 42 papers met the inclusion criteria for the review and were evaluated for quality using the SIGN criteria and data were extracted. A decision was made at this point to remove the studies considered to be at 


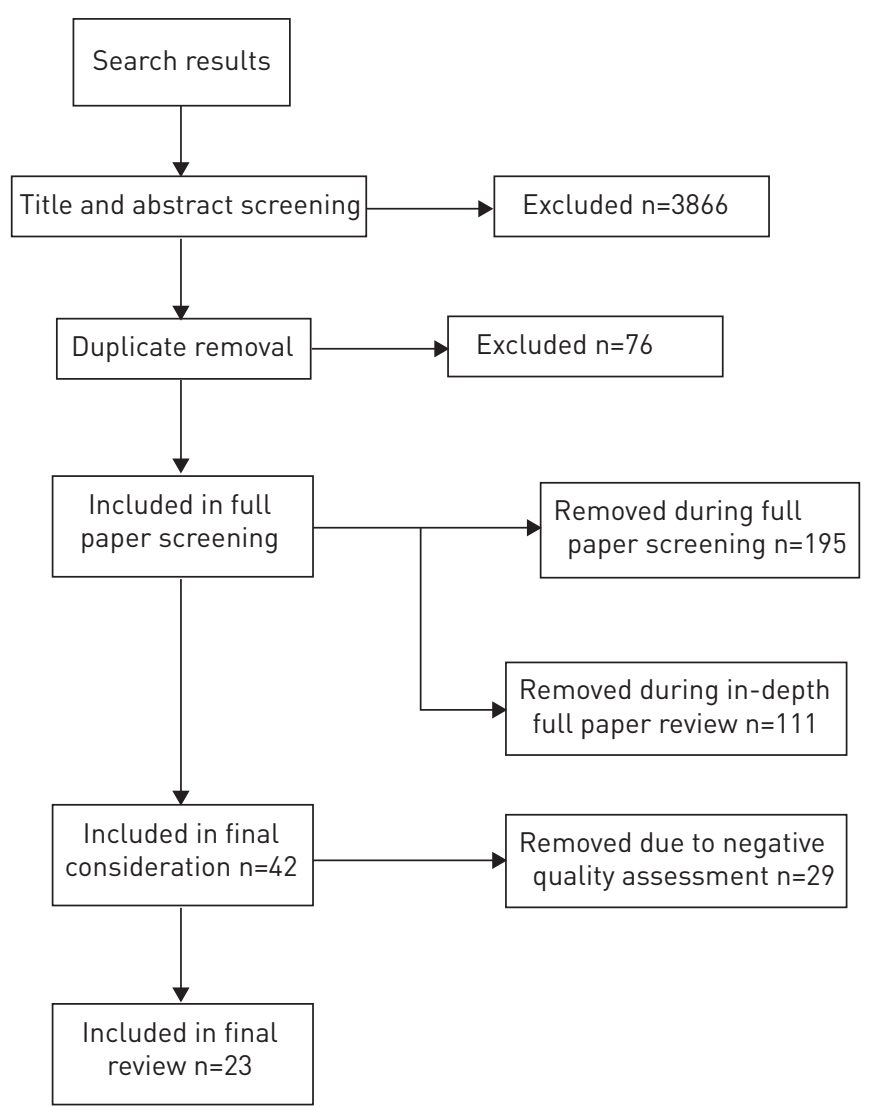

FIGURE 1 Results of searches, screening and data extraction.

high risk of bias (graded "_" in terms of quality), as this would impact on the overall quality of the review. These negatively graded studies are listed in the project report [7].

A complete listing of included studies is presented in table E1. It lists a total of 23 papers, 17 individual studies and six papers from the Agricultural Health Study in America [9-14]. The papers comprised 17 cross-sectional studies, two case-control studies, three cohort studies and one systematic review. Within the paper, the results presented are summarised; for full coverage refer to the full report [7]. The results presented in tables 1-5 are selected odds ratios from included studies for simplicity. For full results, please refer to the original papers.

\section{Pesticide exposure and asthma}

Prevalent asthma in adults

Table 1 includes 12 studies of prevalent asthma in adults. Statistically significant associations were reported in seven studies, although the effect sizes were generally small. Table 2 provides selected odds ratios and full results can be obtained from the original papers.

Many of these studies involved agricultural workers and, while some studies were adjusted for co-exposures to allergens, such as animal dander or crops, these may not have been adequately controlled for where the prevalence of such co-exposures was high. Only one study in adults employed pesticide biomonitoring and this failed to find an association with asthma and ethylenebisdithiocarbamate exposed workers [16].

Several studies $[9,10,17,18]$ identified an association between exposure to organophosphate pesticides, such as parathion and malathion, and asthma.

A Japanese study of 28 workers manufacturing tetrachloroisopthalonitrile (chlorothalonil) found that exposed workers had significantly more asthma-like symptoms than a comparison group of unexposed workers from the same plant [22]. Although bronchial challenge testing was not undertaken, the results are consistent with the known respiratory irritant effects of chlorothalonil. The study did not calculate any odds ratios.

JONES et al. [23] carried out a systematic review and meta-analysis of mortality in crop protection production workers and found that the standardised mortality ratio for bronchitis, emphysema and asthma 
TABLE 1 Pesticide exposure and asthma in adults

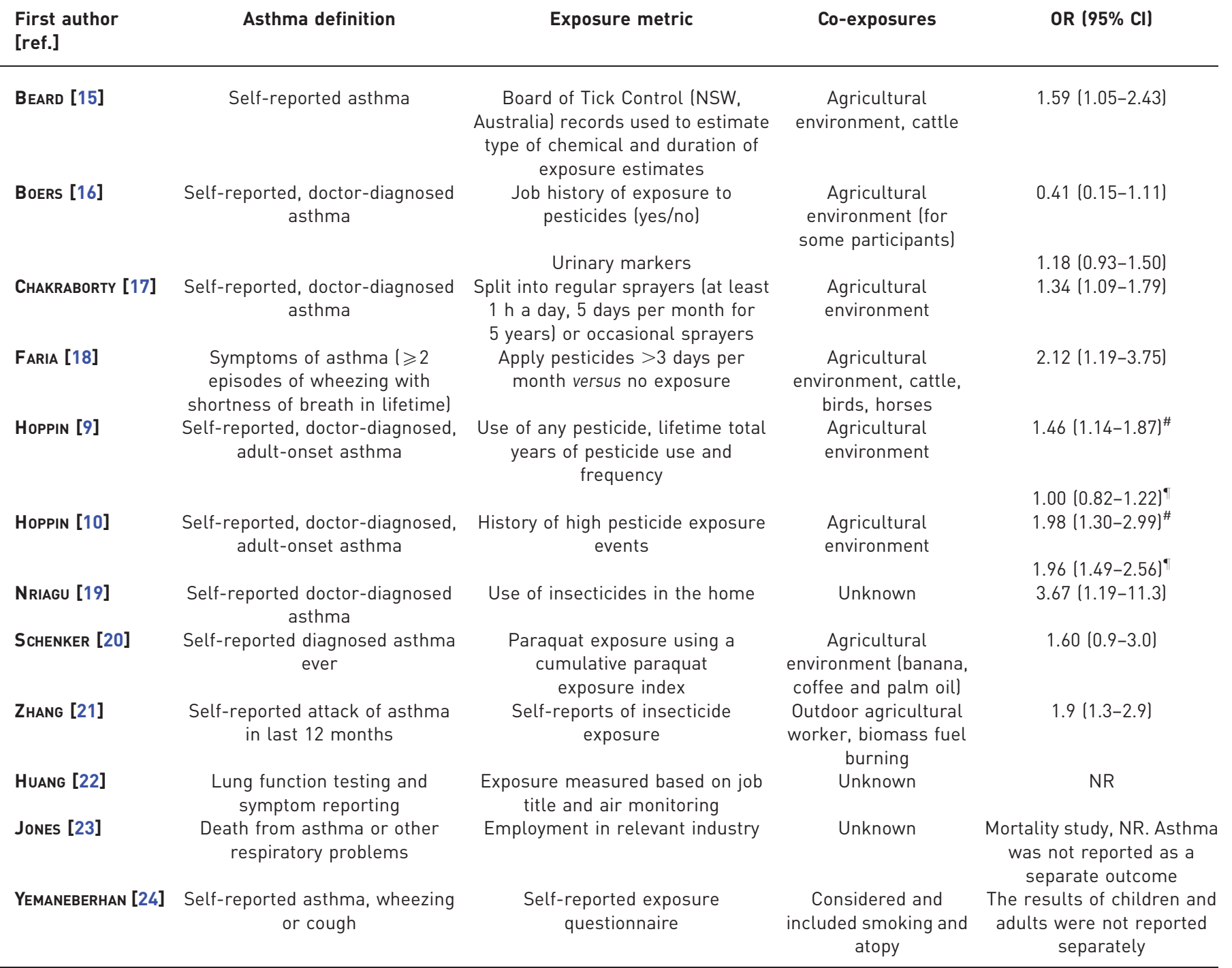

\#: atopic asthma; ": nonatopic asthma. NR: not reported.

TABLE 2 Pesticide exposure and asthma in children

First author [ref.]

Asthma definition

Exposure metric

Co-exposures

OR $(95 \% \mathrm{Cl})$

SALAM [25]

Doctor-diagnosed asthma

Self-reported, doctordiagnosed asthma

Salameh [26]

SUNYER [27]

SUNYER [28]

WESELAK [29]
Doctor-diagnosed asthma at age 4 years

Doctor-diagnosed asthma at age 6.5 years

Self-reported, doctordiagnosed asthma
Self-reported farm-related exposures to crops, dusts, animals, herbicides and pesticides in first year of life Any exposure to pesticides

Cord blood and blood samples

Cord blood and blood samples aged 4 years

Any exposure to pesticides during pregnancy Crops, dusts,
animals

$2.39(1.17-4.89)$

Dust, animals

$1.73(1.02-2.96)$

Unknown

$1.46^{\#}(0.92-2.32)$

Unknown

$1.18(1.01-1.39)$

Farm environment

$1.00(0.71-1.40)$

\# : risk ratio. 
TABLE 3 Pesticide exposure and wheeze in adults

\begin{tabular}{|c|c|c|c|c|}
\hline $\begin{array}{l}\text { First author } \\
\text { [ref.] }\end{array}$ & Wheeze definition & Exposure metric & Co-exposures & OR $(95 \% \mathrm{Cl})$ \\
\hline \multirow[t]{2}{*}{ BoERs [16] } & Self-reported wheeze & $\begin{array}{l}\text { Job history of exposure to } \\
\text { pesticides (yes/no) }\end{array}$ & $\begin{array}{l}\text { Agricultural } \\
\text { environment (for } \\
\text { some subjects) }\end{array}$ & $0.56(0.32-0.98)$ \\
\hline & & Urinary markers & & $0.99(0.87-1.13)$ \\
\hline Сhakraborty [17] & Self-reported wheeze & $\geqslant 50$ cholinesterase inhibition & $\begin{array}{l}\text { Agricultural } \\
\text { environment }\end{array}$ & $2.9(2.1-4.2)$ \\
\hline SCHENKER [20] & $\begin{array}{l}\text { Self-reported } \\
\text { persistent wheeze }\end{array}$ & $\begin{array}{l}\text { Paraquat exposure using a } \\
\text { cumulative paraquat exposure } \\
\text { index }\end{array}$ & $\begin{array}{l}\text { Agricultural } \\
\text { environment (banana, } \\
\text { coffee and palm oil) }\end{array}$ & $1.1(0.7-1.6)$ \\
\hline SPRINCE [30] & $\begin{array}{l}\text { Self-reported "ever } \\
\text { being wheezy" }\end{array}$ & $\begin{array}{l}\text { Self-reports of applying } \\
\text { pesticides to livestock }\end{array}$ & $\begin{array}{l}\text { Agricultural } \\
\text { environment }\end{array}$ & $3.92(1.76-8.72)$ \\
\hline HopPIN [12] & $\begin{array}{l}\text { Self-reported wheeze } \\
\text { in the last } 12 \text { months }\end{array}$ & $\begin{array}{l}\text { Questionnaire of work practices } \\
\text { and exposure }\end{array}$ & $\begin{array}{l}\text { Agricultural } \\
\text { environment }\end{array}$ & $\begin{array}{l}\text { No ORs were calculated for "any } \\
\text { exposure to pesticides" compared to } \\
\text { "no pesticide exposure" }\end{array}$ \\
\hline HopPIN [13] & $\begin{array}{l}\text { Self-reported wheeze } \\
\text { in the last } 12 \text { months }\end{array}$ & Self-reported questionnaire & $\begin{array}{l}\text { Agricultural } \\
\text { environment }\end{array}$ & $\begin{array}{l}\text { No ORs were calculated for "any } \\
\text { exposure to pesticides" compared to } \\
\text { "no pesticide exposure" }\end{array}$ \\
\hline HopPIN [10] & $\begin{array}{l}\text { Doctor-diagnosed } \\
\text { asthma after age } \\
20 \text { years }\end{array}$ & Metric of lifetime pesticide use & $\begin{array}{l}\text { Agricultural } \\
\text { environment }\end{array}$ & $\begin{array}{l}\text { An OR for wheeze and pesticide } \\
\text { exposure was not calculated }\end{array}$ \\
\hline Huang [22] & $\begin{array}{l}\text { Lung function testing } \\
\text { and symptom reporting }\end{array}$ & Job title and air monitoring & Unknown & No ORs were calculated \\
\hline
\end{tabular}

combined was 1.08 (95\% CI 0.86-1.35) based on 23 studies. As it is a mortality study, no odds ratios were calculated. Additionally asthma was not reported as a separate outcome.

YEMANEBERHAN et al. [24] did not report the results of children and adults separately so no odds ratios were included (table 1).

\section{Prevalent asthma in children}

Five studies related pesticide exposure to asthma in children (table 2). This table provides selected odds ratios and full results can be obtained from the original papers. Four out of the five studies found elevated odds ratios (or relative risks in the case of SUNYER et al. [27]). The odds ratios were significant in three of the studies.

SUNYER and co-workers $[27,28]$ reported on a Spanish birth cohort with $95 \%$ and $97 \%$ rates of follow-up at 4 and 6 years, respectively. They measured 2,2-bis( -chlorophenyl)-1,1-dichloroethylene (DDE), the major metabolite of the organochlorine insecticide DDT, in cord blood and first trimester maternal blood samples as markers of antenatal exposure. They found that doctor-diagnosed asthma at age 6.5 years (OR 1.18, 95\% CI 1.01-1.39) but not at age 4 years (risk ratio 1.46, 95\% CI 0.92-2.32) was associated with cord blood levels of DDE at birth.

Wheeze in adults and children

15 papers were found that examined associations between wheeze and pesticide exposure, 11 papers studied adults, three studied children and one studied both. In adults (table 3), four out of the 12 studies showed 
TABLE 4 Pesticide exposure and wheeze in children

\begin{tabular}{|c|c|c|c|c|}
\hline $\begin{array}{l}\text { First author } \\
\text { [ref.] }\end{array}$ & Asthma definition & Exposure metric & Co-exposures & OR $(95 \% \mathrm{CI})$ \\
\hline Salameh [26] & $\begin{array}{l}\text { Self-reported recurrent } \\
\text { wheezing }\end{array}$ & Any exposure to pesticides & Dust, animals & $2.10(1.39-3.18)$ \\
\hline SUNYER [27] & Wheeze at 4 years & $\begin{array}{c}\text { Cord blood and blood samples in } \\
\text { nonatopic children }\end{array}$ & Unknown & $1.37^{\#}(1.06-1.79)$ \\
\hline SUNYER [28] & Wheeze at age 6.5 years & $\begin{array}{l}\text { Cord blood and blood samples aged } \\
\qquad 4 \text { years }\end{array}$ & Unknown & $1.13(1.03-1.39)$ \\
\hline
\end{tabular}

\# : risk ratio.

significant associations of pesticide exposure with wheeze, three of which had OR $>2.0$. Table 3 provides selected odds ratios and full results can be obtained from the original papers.

HoppIN and co-workers [11-13] did not calculate odds ratios for "any exposure to pesticides" compared with "no pesticide exposure" because all participants in the studies were exposed to at least one pesticide due to their occupation.

HoppIN et al. [10] examined the relationship between pesticides and adult-onset asthma in male farmers. The study of 19704 farmers identified that wheeze was reported by $17 \%$ of the control group, $84 \%$ of those with allergic asthma and $70 \%$ of individuals with nonallergic asthma. No odds ratio for wheeze and pesticide exposure was calculated.

HUANG et al. [18] looked at respiratory symptoms in those involved in chlorothalonil production. The survey of 28 workers identified that $21.4 \%$ reported wheezing at work versus none in the reference group.

TABLE 5 Pesticide exposure and bronchitis or chronic obstructive pulmonary disease (COPD) in adults

$\begin{array}{llll}\begin{array}{l}\text { First author } \\ \text { [ref.] }\end{array} & \text { Bronchitis definition } & \text { Exposure metric } & \text { Co-exposures }\end{array}$

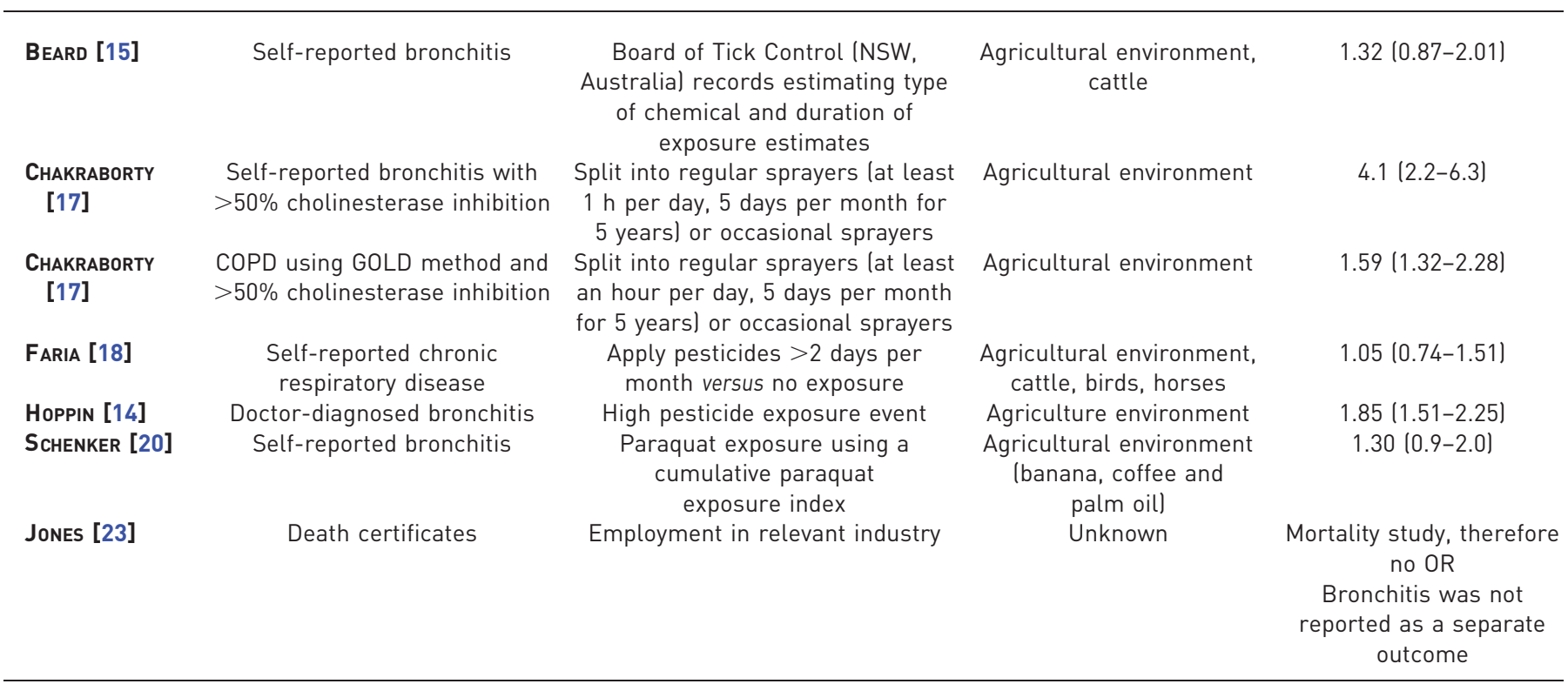

GOLD: Global Initiative for Chronic Obstructive Lung Disease. 
Although bronchial challenge testing was not undertaken, the results are consistent with the known respiratory irritant effects of chlorothalonil. No odds ratios were calculated in the paper.

YEMANEBERHAN et al. [24] did not report the results of children and adults separately, so no odds ratios were included (tables 4 and 5).

In children, three of the four studies showed significant associations of pesticide exposure and wheeze, one of which had an OR $>2.0$ (table 4).

\section{Pesticide exposure and bronchitis or chronic obstructive pulmonary disease}

Six papers investigated associations between either bronchitis or chronic obstructive pulmonary disease (COPD) and pesticide exposure, and are summarised in table 5.

Hoppin et al. [14] examined chronic bronchitis as part of the Agricultural Health Study in the USA. Exposure assessment to pesticides was carried out by obtaining detailed information on the use of 50 pesticides, the total days and years of use of each pesticide and whether they had experienced a high pesticide exposure event. The association between high pesticide exposure event and chronic bronchitis was studied, in addition to the association between individual pesticides and chronic bronchitis.

Three studies reported significant associations [14, 17, 18]; of these, FARIA et al. [18] and HoppIN et al. [14] reported significant associations both with pesticides generally and with organophosphate exposure specifically. CHAKRABORTY et al. [17] reported significant associations with organophosphate and carbamate pesticides. A fourth study by SCHENKER et al. [20] showed a nonsignificant positive association with paraquat exposure.

JONES et al. [23] found that the standardised mortality ratio for bronchitis, emphysema and asthma combined was 1.08 (95\% CI 0.86-1.35). As this was a mortality study, no odds ratios were calculated. Additionally bronchitis was not reported as a separate outcome.

\section{Pesticide exposure and lung function}

Spirometric lung function measures were used as an outcome measure in four studies (table 6).

CHAKRABORTY et al. [17] found an association between reduced lung function and work as a sprayer, and evidence of an exposure-response relationship, with occasional sprayers having higher forced expiratory volume in $1 \mathrm{~s}(\mathrm{FEV} 1) /$ forced vital capacity (FVC) ratios than regular sprayers.

Two studies [20,31] examined paraquat-exposed workers and lung function. Both failed to show any significant differences in lung function between study and control groups.

HUANG et al. [22] examined workers involved in chlorothalonil production. The results indicated that there was a significant reduction in FEV1 and \%FEV (FEV expressed as a percentage of the levels predicted for an individual of the same age and height), but these associations could be considered to be consistent with chlorothalonil's recognised classification as a respiratory irritant. Although no multiple regression analyses (i.e. with multiple predictor variables) were conducted, the exposed and control subjects were very similar in terms of age, height, weight and smoking status. However, no mention was made of socioeconomic status.

\section{Meta-analyses}

The possibilities of carrying out meta-analyses of the studies available for each of the main health endpoints were considered. There were several studies within each health end-point that quantitatively expressed the relationship between exposure to pesticides and occurrence of the end-point, often in the form of odds ratios for those exposed compared with those not exposed. However, the exposure metrics considered within the different studies varied considerably, and it was not appropriate to summarise across them (e.g. it was not appropriate to combine an odds ratio referring to "ever exposed to pesticides" with an odds ratio for "use of insecticides in the home" or an odds ratio for "applying pesticides for $>3$ days per month"). Therefore, no meta-analyses were carried out.

\section{Discussion}

The aim of this systematic review was to assess the evidence for whether there was a relationship between pesticide exposure (both occupational and nonoccupational) and respiratory airways disease, namely asthma, COPD and wheeze. Appraisal of studies evaluated suggested that there was a substantial risk of bias in this overall body of knowledge, and the diversity of exposures precluded us from conducting the planned meta-analyses. The results were, nonetheless, suggestive of potentially adverse associations between pesticide exposure and an increased likelihood of wheezing symptoms and asthma, with the evidence being stronger for an association in children than in adults. In contrast, the overall body of evidence was much weaker for 


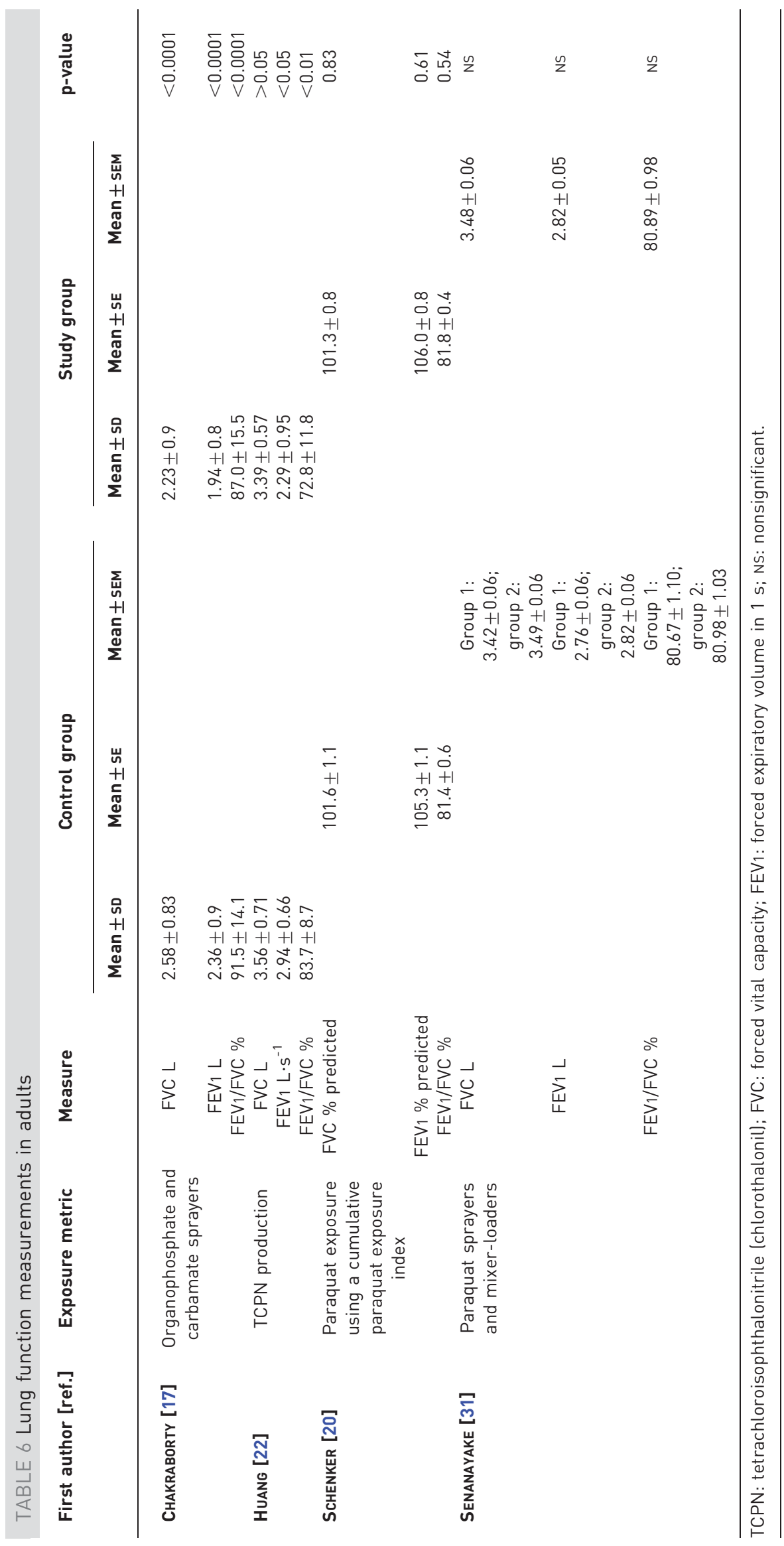


an adverse association between pesticide exposure and an increased likelihood of COPD, with the symptomatic data being finely ambiguous and a notable paucity of studies utilising objective lung function data that is critical for the diagnosis of COPD.

\section{Asthma and wheezing symptoms}

The small number of studies left after the exclusions on methodological grounds limits the strength of the evidence base in this area. Even those included can, in almost every case, be criticised at one level or another, as is the case with all epidemiological studies. Specifically, direct or indirect measurement of exposure to pesticides was rarely reported, and objective measurement of asthma through bronchial responsiveness or serial peak flow measurements has rarely been undertaken. Separation of symptoms soon after exposure, when awareness of symptoms might be higher (especially if the subjects were aware of the purpose of the study) from repeated symptoms whose pattern was initially induced by exposure, cannot be performed with any certainty using cross-sectional or case-control studies. This leaves open the possibility that these associations may not truly be due to asthma. Equally, in many cases, confounders, most notably allergen exposures, were inadequately dealt with, making conclusions on causation difficult.

In the Agricultural Health Study, Hoppin et al. [10] found that a history of a high pesticide exposure event (defined as an incident that gave the individual an unusually high pesticide exposure) was associated with a near doubling of the risk of both atopic and nonatopic asthma. However, the agents associated with these high pesticide exposure events were not specified. Such high pesticide exposure events might reflect worker behaviour, whereby those heavily exposed to pesticides may also be heavily exposed to aeroallergens, such as crop dusts. An alternative explanation is recall bias; asthma sufferers were more likely to recall high pesticide exposure events than nonasthmatics.

In children, a notable study is that by SUNYER et al. [32], who conducted a well-designed prospective birth cohort study with objective measures of exposure (serum levels) prior to the development of disease. In this study, there was minimal attrition during follow-up, the best available outcome parameters in young children were ascertained and multiple-predictor analyses included adjustment for confounders including socioeconomic status. The source of DDE exposure in the children must have been from their mothers, because there were no known environmental releases of DDE in the community from which this cohort was recruited.

Even though the differences in methodological approach prevented formal meta-analysis, a majority of studies reported broadly consistent and coherent associations between pesticide exposure and an increased likelihood of wheezing symptoms and asthma, with the evidence being stronger for an association in children than in adults. In adults the evidence is suggestive but less convincing. There is some consistency between the asthma findings and wheeze findings that would support, at least in some settings, a causal relationship between pesticide exposure and asthma.

The predominance of cross-sectional studies with their temporality constraints limits comment on whether pesticide exposure causes asthma or exacerbates existing (subclinical) asthma. However, a notable highquality birth cohort study [32] strongly suggests a causal association between fetal pesticide exposure via the mother and childhood asthma.

\section{COPD and lung function}

This review suggests that exposure to pesticides could be associated with COPD/chronic bronchitis; however, the strength of evidence with regards to the association is weaker than the association with asthma. There are also fewer studies and, in particular, a lack of studies using lung function to identify COPD, a diagnosis defined by lung function parameters. Hoppin et al. [14] identified multiple pesticide associations with chronic bronchitis, including organophosphates, organochlorines, carbamates and herbicides. It seems unlikely that such a diverse range of agents would all induce chronic bronchitis and to what extent residual confounding (perhaps by agricultural co-exposures such as other pesticides, animal dander, crop dusts, endotoxin or diesel exhaust) might explain these associations is unclear.

\section{Biological plausibility}

An adverse association between pesticide exposure and the airway diseases of asthma and COPD is biologically plausible. Organophosphate and carbamate pesticides inhibit acetyl cholinesterase that in the context of respiratory symptoms results in mucus hypersecretion and, potentially, airway smooth muscle contraction (bronchospasm). This will result in breathlessness, cough and wheeze that could occur in high doses in normal individuals (albeit reversibly), but will probably be a cause of greater reaction in those with pre-existing conditions, such as asthma or COPD. CHAKRABORTY et al. [17] found that workers with $>50 \%$ cholinesterase inhibition were more likely to have doctor-diagnosed asthma than the reference group who 
had $<50 \%$ cholinesterase inhibition. One of the effects of acute organophosphate poisoning is bronchospasm [33], raising the possibility that the observed association reflects acute organophosphate pesticide poisoning rather than a chronic effect.

Immunological studies suggest that pesticide exposure favours the T-helper cell (Th) type 2 immunophenotype associated with asthma and allergy. Blood levels of interleukin (IL)-5 are elevated in children exposed to chlordane in the residential setting [34]. In occupational settings, blood levels of DDT, DDE and hexachlorobenzene have been associated with elevated levels of IL-4 and decreased levels of interferon (IFN) $-\gamma[35,36]$. In subjects who have suffered lindane poisoning in an occupational setting, blood IL-4 levels are elevated and IFN- $\gamma$ decreased [37]. Early life exposure to pesticides is potentially particularly relevant to the development of asthma because this is the time when the first critical interactions between the immune system and allergens occurs; furthermore, it has also been demonstrated that development of the immune system into broadly Th1 and Th2 patterns occurs in most children before the age of 5 years [38].

Pesticides have also been associated with neutrophilic airway inflammation characteristic of COPD and chronic bronchitis. Organochlorine compounds induce neutrophil activation in murine models: permethrin exposure increases murine neutrophilic generation of toxic reactive oxygen molecules $[39,40]$ and dieldrin induces neutrophilic inflammation [41]. In humans, in vitro administration of the organochlorine toxaphene activates neutrophils and the release of the reactive oxygen molecule superoxide [42]. In vitro incubation of human lung alveolar cells with paraquat induces the release of toxic reactive oxygen molecules and the activation of the pro-inflammatory genes $I L-1 A, I L-6$ and $I L-8$ [43]. In humans, the organochlorine insecticide dieldrin increases human neutrophil reactive oxygen molecule production and the secretion of the pro-inflammatory mediator IL-8. In children exposed to chlordane in the residential setting, blood levels of IL-8 have been reported to be elevated [34].

\section{Limitations of included papers}

When exploring an association between an occupational or environmental exposure and a health outcome, robust exposure measurements increase the likelihood of detecting an association, should one exist. Ideally biomonitoring for the agent/metabolite or biological effect monitoring would be employed. While this is possible for acute exposure to some pesticides (e.g. organophosphates and carbamates), only organochlorine insecticides have long-term biomarkers of exposure. As a consequence, historical cohort studies and casecontrol studies typically rely on exposure surrogates, such as ever/never exposed, years of exposure and job title (an imprecise exposure surrogate in agricultural work) [44], or qualitative estimates of pesticide exposure generated by a job or task exposure matrix [45].

Many of the reviewed studies were affected by limitations in the exposure metrics employed, often relying on exposure surrogates, such as self-reported exposure and/or imprecise exposure categories, such as ever/ never exposed to pesticides [25]. Most studies relied on questionnaires to characterise likely exposures; an approach that can be vulnerable to recall bias and exposure misclassification. Relatively few studies employed biomonitoring to measure pesticide exposure [16, 28, 32] or biological effect monitoring [17]. A particular issue arose for those studies in agricultural settings where self-reports of pesticide exposure were used, but co-exposures to other agricultural respiratory hazards (e.g. grain dust, animal dander and endotoxins) were often not evaluated. This was compounded by small sample sizes in some papers; however, the samples were restricted to those who were actually exposed to particular pesticides, rather than a range of agents.

Given the likely association between socioeconomic status and pesticide exposure, and the reported association between socioeconomic status and asthma [46-49], any study of pesticides and asthma should adjust for the potentially confounding effects of socioeconomic status. Failure to adjust for socioeconomic status is likely to introduce a systematic bias in favour of an adverse association between pesticide exposure and asthma and wheezing symptoms. The failure to adjust for socioeconomic status is a notable weakness of some studies reporting associations between pesticides and asthma in adults. While some of the reported studies in adult populations are likely to be biased, it is notable that one longitudinal birth cohort study in children is of high quality, employing a prospective design, objective exposure assessment, ascertainment of best available paediatric asthma outcome and rigorous adjustment for potentially confounding factors.

No studies in the literature reviewed here used bronchial responsiveness testing and the questionnaires used were often not identifiable as validated and accepted asthma questionnaires. When doctor-diagnosed asthma was used as a health outcome, it is possible that doctors may be more likely to diagnose asthma if they are aware of their occupational exposure. 
Six of the papers included were based on the Agricultural Health Study [9, 10, 11-14]. There are a number of difficulties associated with using the Agricultural Health Study. These include failure to suitably adjust for socioeconomic status and the transferability of its findings to other settings. Furthermore, the studies involve multiple analyses of the same dataset, resulting in significant overlap where exposure to one agent is highly correlated with exposure to another agent. Although the study population was large within the Agricultural Health Study, the exposure measurement was based on exposure to multiple agents. Thus, a broad picture of potential associations can be viewed, but little further knowledge is available regarding particular agents or groups of chemicals. However, the review has been balanced with the use of smaller studies, which may be methodologically weaker but can focus on particular agents.

Additionally, some papers studied pesticides that are no longer used in some countries, e.g. DDT and heptachlor are not used in the UK; therefore, those results will not be as relevant to some countries as studies using currently approved pesticides. Most, if not all, of the reported studies assume that any adverse effect is a consequence of the active pesticide constituent. Consequently, one of the limitations of this review is the inability to exclude the possibility that any reported adverse health effect of a pesticide may in reality be an adverse effect of co-formulant(s) in currently approved commercial pesticide preparations.

\section{Strengths and limitations}

The searches we employed were comprehensive; quality assessment was rigorous and conducted by two investigators to ensure concordance. The limitations of this work stem primarily from the lack of intervention studies, with the majority of studies being cross-sectional, inconsistent exposure assessment at different time-points (antenatal, children and adults), a lack of research on individual pesticides and relatively few studies employing pulmonary function testing. In the light of the marked heterogeneity of exposure assessments, we considered it inappropriate to conduct the planned meta-analyses. We were also unable to formally test for publication bias.

Another potential concern is the possible adverse effects of more widespread bystander and nonoccupational pesticide exposure (e.g. those living in areas where spraying occurs). Given the different natures of occupational and nonoccupational exposure (e.g. lower dose nonoccupational) it is not possible to translate the associations reported in occupational studies to the general population. However, possible adverse effects of nonoccupational exposures cannot be easily dismissed. SUNYER et al. [27] reported an association between nonoccupational exposure and doctor-diagnosed asthma and parental-reported wheeze.

Although 42 papers met our inclusion criteria, 19 were considered to be at high risk of bias and were excluded because of their impact on the overall quality of the review. It was noticeable that seven of the 19 low-quality papers failed to adjust for cigarette smoking, a major trigger of respiratory symptoms and the most important risk factor for COPD [50].

There is some consistency between the asthma findings and wheeze findings that would support, at least in some settings, a causal relationship between pesticide exposure and asthma. However, while often used as a surrogate for asthma in epidemiological studies, especially in children, wheeze is a manifestation of narrowed airways, irrespective of aetiology. Wheeze was included in this review as it is frequently used as a surrogate for asthma. However, not all cases of wheeze will be as a result of asthma, most notably the wheezing symptoms occurring during viral respiratory tract infection, so this adds further uncertainty and caution should be taken when associating wheeze and asthma.

\section{Conclusions}

While the quality of most papers in this report are open to criticism, there is sufficient evidence to suggest that exposure to pesticides (or its surrogate) may be associated with a greater prevalence of asthma and wheeze, especially in children. In adults the evidence is suggestive but less convincing. The evidence for pesticides contributing to COPD is suggestive at best. At present the evidence is insufficient to identify specific causative pesticides or pesticide groups.

Associations between pesticide exposure and asthma and COPD are mechanistically plausible, with pesticide agents being reported to influence the immunological and neutrophilic inflammatory processes characteristic of asthma and COPD, respectively.

This systematic review clearly highlights the need for further high-quality research to demonstrate causality between pesticide exposure and asthma and to show, using lung function measurements, whether pesticide exposure is associated with COPD. Any future studies need to consider issues of co-exposure and confounding by nonpesticide exposures and factors. 


\section{Acknowledgements}

We would like to thank the Dept for Environment, Food and Rural Affairs (Defra; London, UK) for funding the research project.

\section{References}

Lombardo LJ, Balmes JR. Occupational asthma: a review. Environ Health Perspect 2000; 108: 697-704.

2 Asher MI, Montefort S, Bjorksten B, et al. Worldwide time trends in the prevalence of symptoms of asthma, allergic rhinoconjunctivitis, and eczema in childhood: ISAAC phases one and three repeat multicountry cross-sectional surveys. Lancet 2006; 368: 733-743.

3 Weinmayr G, Weiland SK, Björkstén B, et al. Atopic sensitization and the international variation of asthma symptom prevalence in children. Am J Respir Crit Care Med 2007; 176: 565-574.

4 European Community Respiratory Health Survey. Variations in the prevalence of respiratory symptoms, selfreported asthma attacks and the use of asthma medication in the European Community Respiratory Health Survey (ECHRS). Eur Respir J 1996; 9: 687-695.

5 Janson C, Anto J, Chinn S, et al. The European Community Respiratory Health Survey: what are the main results so far? Eur Respir J 2001; 18: 598-611.

6 American Thoracic Society. Respiratory health hazards in agriculture. Am J Respir Crit Care Med 1998; 158: Suppl. 5, S1-S76.

7 Crawford JO, Doust E, Dick FD, et al. A systematic review of the literature on asthma prevalence and exacerbation and other respiratory diseases in association with pesticide exposure. Report number 603-00535, IOM, Edinburgh, 2012.

8 Scottish Intercollegiate Guidelines Network. SIGN 50: A Guideline Developer's Handbook. www.sign.ac.uk/ guidelines/fulltext/50/index.html Date last accessed: December 18, 2013.

9 Hoppin JA, Umbach DM, London SJ, et al. Pesticides and atopic and nonatopic asthma among farm women in the Agricultural Health Study. Am J Respir Crit Care Med 2008; 177: 11-18.

10 Hoppin JA, Umbach DM, London SJ, et al. Pesticide use and adult-onset asthma among male farmers in the Agricultural Health Study. Eur Respir J 2009; 34: 1296-1303.

11 Hoppin JA, Umbach DM, London SJ, et al. Chemical predictors of wheeze among farmer pesticide applicators in the Agricultural Health Study. Am J Respir Crit Care Med 2002; 165: 683-689.

12 Hoppin JA, Umbach DM, London SJ, et al. Pesticides associated with wheeze among commercial pesticide applicators in the Agricultural Health Study. Am J Epidemiol 2006; 163: 1129-1137.

13 Hoppin JA, Umbach DM, London SJ, et al. Pesticides and adult respiratory outcomes in the agricultural health study. Ann NY Acad Sci 2006; 1076: 343-354.

14 Hoppin JA, Valcin M, Henneberger PK, et al. Pesticide use and chronic bronchitis among farmers in the Agricultural Health Study. Am J Ind Med 2007; 50: 969-979.

15 Beard J, Sladden T, Morgan G, et al. Health impacts of pesticide exposure in a cohort of outdoor workers. Environ Health Perspect 2003; 111: 724-730.

16 Boers D, van Amelsvoort L, Colosio C, et al. Asthmatic symptoms after exposure to ethylenebisdithiocarbamates and other pesticides in the Europit field studies. Hum Exp Toxicol 2008; 27: 721-727.

17 Chakraborty S, Mukherjee S, Roychoudhury S, et al. Chronic exposures to cholinesterase-inhibiting pesticides adversely affect respiratory health of agricultural workers in India. J Occup Health 2009; 51: 488-497.

18 Faria NM, Facchini LA, Fassa AG, et al. Pesticides and respiratory symptoms among farmers. Rev Saude Publica 2005; 39: 973-981.

19 Nriagu J, Robins T, Gary L, et al. Prevalence of asthma and respiratory symptoms in south-central Durban, South Africa. Eur J Epidemiol 1999; 15: 747-755.

20 Schenker MB, Stoecklin M, Lee K, et al. Pulmonary function and exercise-associated changes with chronic low-level paraquat exposure. Am J Respir Crit Care Med 2004; 170: 773-779.

21 Zhang LX, Enarson DA, He GX, et al. Occupational and environmental risk factors for respiratory symptoms in rural Beijing, China. Eur Respir J 2002; 20: 1525-1531.

22 Huang J, Aoyama K, Ueda A, et al. Respiratory effects and skin allergy in workers exposed to tetrachloroisophthalonitrile. Bull Environ Contam Toxicol 1995; 55: 320-324.

23 Jones DR, Sutton AJ, Abrams KR, et al. Systematic review and meta-analysis of mortality in crop protection product manufacturing workers. Occup Environ Med 2009; 66: 7-15.

24 Yemaneberhan H, Bekele Z, Venn A, et al. Prevalence of wheeze and asthma and relation to atopy in urban and rural Ethiopia. Lancet 1997; 350: 85-90.

25 Salam MT, Li YF, Langholz B, et al. Early-life environmental risk factors for asthma: findings from the Children's Health Study. Environ Health Perspect 2004; 112: 760-765.

26 Salameh PR, Baldi I, Brochard P, et al. Respiratory symptoms in children and exposure to pesticides. Eur Respir J 2003; 22: 507-512.

27 Sunyer J, Torrent M, Munoz-Ortiz L, et al. Prenatal dichlorodiphenyldichloroethylene (DDE) and asthma in children. Environ Health Perspect 2005; 113: 1787-1790.

28 Sunyer J, Torrent M, Garcia-Esteban R, et al. Early exposure to dichlorodiphenyldichloroethylene, breastfeeding and asthma at age six. Clin Exp Allergy 2006; 36: 1236-1241.

29 Weselak M, Arbuckle TE, Wigle DT, et al. In utero pesticide exposure and childhood morbidity. Environ Res 2007; 103: 79-86.

30 Sprince NL, Lewis MQ, Whitten PS, et al. Respiratory symptoms: associations with pesticides, silos, and animal confinement in the Iowa Farm Family Health and Hazard Surveillance Project. Am J Ind Med 2000; 38: 455-462.

31 Senanayake N, Gurunathan G, Hart TB, et al. An epidemiological study of the health of Sri Lankan tea plantation workers associated with long term exposure to paraquat. $\mathrm{Br}$ J Ind Med 1993; 50: 257-263.

32 Sunyer J, Garcia-Esteban R, Alvarez M, et al. DDE in mothers' blood during pregnancy and lower respiratory tract infections in their infants. Epidemiology 2010; 21: 729-735.

33 Eddleston M, Buckley NA, Eyer P, et al. Management of acute organophosphorus pesticide poisoning. Lancet 2008; 371: 597-607. 
Phillips TM. Assessing environmental exposure in children: immunotoxicology screening. J Exp Sci Environ Epidemiol 2000; 10: 769-775.

35 Daniel V, Huber W, Bauer K, et al. Associations of dichlorodiphenyltrichloroethane (DDT) 4.4 and dichlorodiphenyldichloroethylene (DDE) 4.4 blood levels with plasma IL-4. Arch Environ Health 2002; 57: 541-547.

36 Daniel V, Huber W, Bauer K, et al. Associations of blood levels of PCB, HCHS, and HCB with numbers of lymphocyte subpopulations, in vitro lymphocyte response, plasma cytokine levels, and immunoglobulin autoantibodies. Environ Health Perspect 2001; 109: 173.

37 Seth V, Ahmad RS, Suke SG, et al. Lindane-induced immunological alterations in human poisoning cases. Clin Biochem 2005; 38: 678-680.

38 Yabuhara A, Macaubas C, Prescott SL, et al. TH2-polarized immunological memory to inhalant allergens in atopics is established during infancy and early childhood. Clin Exp Allergy 1997; 27: 1261-1269.

39 Gabbianelli R, Falcioni ML, Nasuti C, et al. Effect of permethrin insecticide on rat polymorphonuclear neutrophils. Chem Biol Interact 2009; 182: 245-252.

40 Olivero J, Bezdecny SA, Ganey PE. A molecular motif required for the activation of rat neutrophil phospholipase A2 by organochlorine compounds. Chem Res Toxicol 2002; 15: 153-159.

41 Pelletier M, Roberge CJ, Gauthier M, et al. Activation of human neutrophils in vitro and dieldrin-induced neutrophilic inflammation in vivo. J Leukoc Biol 2001; 70: 367.

42 Gauthier M, Roberge CJ, Pelletier M, et al. Activation of human neutrophils by technical toxaphene. Clin Immunol 2001; 98: 46-53.

43 Mitsopoulos P, Suntres ZE. Cytotoxicity and gene array analysis of alveolar epithelial A549 cells exposed to paraquat. Chem Biol Interact 2010; 188: 427-436.

44 MacFarlane E, Benke G, Del Monaco A, et al. Cancer incidence and mortality in a historical cohort of Australian pest control workers. Occup Environ Med 2009; 66: 818-823.

45 Dick FD, Semple SE, Van Tongeren M, et al. Development of a Task-Exposure Matrix (TEM) for Pesticide Use (TEMPEST). Ann Occup Hyg 2010; 54: 443-452.

46 Forno E, Celedon JC. Asthma and ethnic minorities: socioeconomic status and beyond. Curr Opin Allergy Clin Immunol 2009; 9: 154-160.

47 Bacon SL, Bouchard A, Loucks EB, et al. Individual-level socioeconomic status is associated with worse asthma morbidity in patients with asthma. Respir Res 2009; 10: 125.

48 Bryant-Stephens T. Asthma disparities in urban environments. J Allergy Clin Immunol 2009; 123: 1199-1206.

49 Ekerljung L, Sundblad B, Rönmark E, et al. Incidence and prevalence of adult asthma is associated with low socioeconomic status. Clin Respir J 2010; 4: 147-156.

50 Polosa R, Thomson NC. Smoking and asthma: dangerous liaisons. Eur Respir J 2013; 41: 716-726. 